\title{
A New Learning and Service Platforms in Universities in World of 2.0
}

\author{
Moses C. Nwosu, Stella Agu \\ Abia State University Library Uturu, Abia, State Nigeria
}

\begin{abstract}
This is a reflective paper based on authors' observation, experience and review of the related literature. The paper examines the 2.0 phenomenon and the ways in which the digital age has impacted the infrastructure of university education and its delivery. It discusses this paradigm shifts and the roles of teachers, librarians and students in Nigerian universities. The paper reveals that we are witnessing changes of approach to knowledge generation and learning outcomes and to more collaborative ways of working. Ways that harness the collective skills, knowledge and effort of all those involved in our learning communities, that transform practice to more accurately reflect the way we live and work. The paper recommends among others; changes of approach from instructional paradigm to learning paradigm, blended learning -[ synchronous and asynchronous methods] as well as more collaborative ways of working between librarians and educators such that can help the latter to look towards technology as normal and not as something strange or remote.
\end{abstract}

\section{Introduction}

Educators in the 21st century are confronted with the realization that students entering the classroom today are much different from those who have come before. As a result, today's students are demanding a change in the classroom because they are enmeshed in technology and have the ability to gather information faster than any other generation. What is bringing about this is the new 2.0 platform that has come into focus through the Web. The 2.0 phenomenon has become a buzzword in the world of learning. 2.0 has become the common denominator in academia as well as in most occupations and professions. This buzzword " 2.0 " has recently been thrown around as if it were a software package that one can upload into the brain to achieve new understanding. Within a period of less than a decade, the "2 0 " meme - [an idea, behaviour, or style that spreads from person to person within a culture] has risen from obscurity to mainstream in the world of learning. Although there is no such magical fountain of wisdom, there are real promises of efficiency and effectiveness in "2.0". The 2.0 "up the chain" metaphor can be described as the use of emergent social software platforms within organisations, or between organisations and their partners or customers. The organisation that comes to mind in this discourse is the university. Referred to in this context as 'University 2.0 '

What exactly does 2.0 mean? The question is perhaps particularly urgent because the Web 2.0 meme has become so widespread that organisations are now pasting it on as a marketing buzzword, with no real understanding of just what it means. For [3] the 2.0 meme gave Learning 2.0 the traction it needed to get implemented in the university classrooms and libraries. The question still hangs: could such have happened without Classroom 2.0 and Library 2.0?

[9] whimsically states:

"Classroom 2.0 isn't a program or at least any one program. It's a mindset, a style, a way of encountering the learner, and the learner encountering back. The classroom 1.0 model has teachers in the place of authority. The students enter the classroom, receive the knowledge, and then spit it out on a test. Some classes utilize student feedback, but from my experience many either do or don't have the chance. Enter Classroom 2.0."

In today's progressive classrooms, 2.0 and libraries 2.0, yesterday's rows of quiet student listeners and readers have given way to small groups of active learners, thoroughly engaged in discussions and explorations even in libraries that were once noiseless zones. On his part [7] defines Library 2.0 as "a subset of library services designed to meet user needs caused by the direct and peripheral effects of Web 2.0". Library 2.0 is a change in interaction between users and libraries in a new culture of participation catalysed by web technologies [8]. Web 2.0 talks to the changes wrought in the wideopen Web. It is one that speaks to the changes that these technologies, cultures and practices can have on our classrooms, our libraries and our own enterprises. The global web 2.0 discussion is birthing a number of newborn babies: advertising 2.0, classroom 2.0, e-learning 2.0, enterprise 2.0, librarian 2.0, library 2.0, pedagogy 2.0, school 2.0, teacher 2.0, university 2.0 and Web 2.0 among others. Today, it is fashionable for people of all shades and sizes to add or prefix the term 2.0 to their 
professional calling. It has therefore, become a lot easier to understand how 2.0 may be slipping inside our university's firewalls already. When it does come inside our classrooms and information service industry, it could morphs into something called Classroom 2.0 and Library 2.0 which impacts on our culture of service and romance with technology and learning outcomes. In this regard, the teacher Instead of standing in front or in the center to deliver instruction, he or she is apt to be on the move, observing, asking questions, and guiding students to make their own sense of the world of learning 2.0. Even the classroom walls have expanded, with technologies connecting students to the wider global community. In his/her new environment, the librarian requires a "different mindset or attitude" which is "challenging the mental models" and forcing him to think about and perceive the profession differently. In many institutions, the Internet has opened access to a vast world of information, and students are learning criticalthinking skills to filter out the noise and decide which sources are reliable and which information to trust. To make authentic connections with students, the strategies must be changed to fit this new age of students.

Formal education as [4] observes is also being impacted by the movement of knowledge creation and dissemination towards the Web. As a result, learning is no longer happening solely in the classroom and the divisions between learning, work and recreation are becoming increasingly blurred. Individuals employ social networks to connect friends, stay informed professionally, and engage with others in learning communities. Learning as it were, is open, networked and always happening. This shift in the way people are learning has led many educational theorists to wonder whether traditional pedagogies are adequate to engage and educate the current generation of students. According to [15] In this learning landscape there is a need to rethink models for teaching and learning in order to replace outmoded 'closed classroom' models which place emphasis on the delivery of information by an instructor and/or from a textbook rather than being learner-centric

Three reasons account for this transition namely:

1. New Technology,

2. The New Generation of Students Known as Generation X and Y.; and,

3. Paradigm Shifts to New Model of Learningemphasis on better learning and teaching methods.

These changes in society are motivating innovative university educators and instructors to re- think pedagogy and teaching methods. Within the past twenty years, the environment in which people learn has changed significantly. The impact of technology particularly the Internet has made it possible for people to access information at the point of need, rendering the ability to find information more important than mastery of knowledge in any one area. Knowledge, according to [4] is no longer thought of as immutable; something one can learn once and forever be considered informed. Today, in many professions, what one needs to know to be considered informed is constantly changing, making it necessary to think of learning as a continuous lifelong endeavour. The Internet has opened up a world of learning beyond the formal classroom, offering people opportunities to develop their own personal learning environments. In recent years, a couple of things have been more disruptive to education than participatory technologies and Web 2.0. Web 2.0 was built on an "architecture of participation," where users are both consumers and producers [prosumers] of information. This was the real intention of the Creator of the World Wide Web, Tim Berners---Lee. But it was not until the early 21 st century that participation in the creation of knowledge on the Web started to become a mainstream activity. The reason for this shift to take place was that Web 2. 0[the tools for participation] became easier to use. Sharing knowledge and media is as easy as typing words in a keyboard or clicking a button and so becomes something that anyone with Internet access can do. The development and application of Web 2.0 technologies, such as Facebook, Twitter, YouTube and others have not only increased in popularity in recent years but more importantly made it possible for anyone to share their ideas with the world. These new applications allow users to interact and collaborate with each other via social media in a virtual community [14].

Along with these changes, tertiary student profiles indicate that most students now juggle work and study, are technology savvy, and use social networking tools as a central part of their academic and social lives (Windham, 2005).

Education in today's media rich society must be ready to grapple with the significant pedagogic, cultural and social changes associated with technological innovation. While there are cases of innovation and transformation of pedagogies, there remain many exemplars of outmoded traditional curricular and didactic instruction that merely replicate face-to-face teaching rather than innovations that make best use of interactive tools and technologies. However, the literature surrounding Web 2.0 use or deployment in the classroom 2.0 and the role of librarian 2.0 and teacher 2.0 does not seem to be lacking nor was there evidence of underlying pedagogy 2.0 and how it can be applied to facilitate the intended learning 
outcomes. On the strength of this, the paper sets out to examine the reasons for this paradigm shift.

\section{Conceptual Analysis}

Open classroom is not a new concept. In 1980 Michael Woods wrote that open classroom contrasts with more "traditional" modes of schooling in many aspects as the teacher's role becomes more of a nonauthoritarian "catalyst" to learning and the pupil role becomes more active in terms of the content and pacing of work, with an emphasis on self-motivation and self-discipline. At that moment concept was not so much related with technology, as it is now. The concept of the open classroom according to [21] is changing, partly because of the impact of Web 2.0 on technology enhanced learning. Open Classroom 2.0 can be defined as an open learning environment which consists of some Web 2.0 style technological solutions, but also embraces some of the innovative learning and teaching methods. [21] puts forward the question. So, why Classroom 2.0? Classroom 2.0 is the term used to describe an educational environment that utilizes Web 2.0 and other collaborative technologies to improve student learning. Classroom 2.0 redefines the meanings of the teacher, the student and responsibility. It also means a shift in the relationships to curriculum and technologies. Moving to a Classroom 2.0 model can be challenging for both students and teachers, and the shifts in power and responsibility must be anticipated, acknowledged and negotiated carefully and transparently.

Pedagogy 2.0 represents a set of approaches and strategies that differs from teaching as a didactic practice of passing on information; instead, it advocates a model of learning in which students are empowered to participate, communicate, and create knowledge, exercising a high level of agency and control over the entire learning process [www.igiglobal.com/dictionary/pedagogy-2-0/22171]. It is a framework that aims to focus on desired learning outcomes in order to exploit more fully the affordances and potential for connectivity enabled by Web 2.0 and social software tools. It is envisioned as an overarching concept for an emerging cluster of practices that advocates learner choice and self direction as well as engagement in flexible, relevant learning tasks and strategies. Pedagogy 2.0 is a learning ecology that unlocks the benefits of participatory technologies. It lets go of the idea of the classroom as a walled garden that contains everything students need to learn about a topic. Pedagogy 2.0 also acknowledges that in a networked society, powered by a range of high-speed technologies, learners have access to ideas, resources, and communities to support their learning, are driven by personal needs and choice (personalization), and are able to develop self- regulatory skills. A defining feature of Pedagogy 2.0 is that, alongside the increased socialization of learning and teaching, there is a focus on a less prescriptive curriculum and a greater emphasis on teacher-student partnerships in learning, with teachers as co-learners.

Although not dependent on new technology, [15] Pedagogy 2.0 capitalizes on the core energies and affordances of Web 2.0 - a raft of tools that support user autonomy, increased levels of socialization and interactivity, access to open communities, and peerto-peer networking - in order to move beyond instructor-centered classroom environments, prescribed curricula and content, and the "walled garden" approach of learning management systems.

Library 2.0 is the natural evolution of library services to a level where the library user is in control of how and when he/she gets access to the services he/she needs and wants. According to [13] Library 2.0 is the application of interactive, collaborative, and multi-media web-based technologies to webbased library services and collections. The major focus of Library 2.0 centres on keeping those [users] you have while at the same time enticing those who do not currently use the library in addition to exploring multiple niche groups and their needs. To perform effective service ideas and technologies that assist in delivering services to niche groups.

\section{Web 2.0 and Education}

Web 2.0 is a term that appears to have strong associations within the educational sector.

Web 2.0 tools change the way people interact [1] offering a wealth of learning opportunities for students. However, the use of Web 2.0 in the classroom is expected to change the way in which teachers deliver their lessons and how they fulfill the learning expectations of students. It is important that educators adopting the use of Web 2.0 understand the pedagogy of Web 2.0- Pedagogy 2.0 prior to introducing a Web 2.0 tool into the classroom 2.0. Indeed, Web 2.0 which centres on the idea of a collective intelligence, changed the role of the World Wide Web; it is not only a way to bring information any more, rather it has been configured around activities of people. Typical features of Web 2.0 tools are the participatory characteristics, mutual contribution, content and resource sharing, users' active role and interaction resulting in the development of online social communities. In that way, it seems that we are destined to be residents, and not visitors, with technologies . The term 'Web 2.0' was coined by technology commentator Tim O'Reilly who defined it as follows:

Web 2.0 is the network as platform, spanning all connected devices; Web 2.0 applications are those that make the most of the intrinsic advantages of that platform: delivering software 
as a continually-updated service that gets better the more people use it, consuming and remixing data from multiple sources, including individual users, while providing their own data and services in a form that allows remixing by others, creating network effects through an 'architecture of participation' and going beyond the page metaphor of Web 1.0 to deliver rich user experiences [17].

Since 2005, the emergence of Web 2.0 has increased democracy, creativity and openness of the Web usage in general, allowing everyone to become an author, producer or publisher. It is inevitable that Web 2.0 is going to change also the way teachers and students learn with computers. Learning 2.0 is the utilization of proven learning principles applied in the context of self-directed or self-directed-hybrid learning, Web tools, and social networking and collaboration. While not designed specifically for educational purposes, Web 2.0 tools provide unique, hitherto impossible, opportunities to change the process of teaching and the nature of learning experiences and have a positive effect on several contemporary educational challenges such as student engagement, authentic learning, and autonomy in learning. Nowadays, students spend a lot of time online using Web 2.0 services to express their views and meet with friends.

Traditional online learning platforms have expanded to accommodate chats, wikis, blogs, video sharing, and virtual worlds, all of which increase student-to-student and student-to-faculty interactions. Blogs and wikis are fundamentally 2.0, and their global proliferation has enormous implications for libraries and the 21st century world of learning. Even more importantly, social media sites have elevated network building and sharing capabilities, which can be tailored for individual courses to facilitate communication and learning. Table 1 presents common Web 2.0 tools useful for students/learners online pedagogy.

Table 1. Web 2.0 Tools

\begin{tabular}{|c|c|c|}
\hline Web 2.0 Tool & Category & 21st Century Skill \\
\hline Blogs & Post \& Comment & $\begin{array}{l}\text { Creativity \& Innovation, Critical Thinking \& } \\
\text { Problem Solving, Communication, Information } \\
\text { Literacy, ICT Literacy, Initiative \& Self-direction, } \\
\text { Leadership \& Responsibility }\end{array}$ \\
\hline Wiki & Collaborative Productivity & $\begin{array}{l}\text { Creativity \& Innovation, Collaboration, } \\
\text { Information Literacy, ICT Literacy, Flexibility \& } \\
\text { Adaptability, Productivity \& Accountability }\end{array}$ \\
\hline Twitter & Knowledge Sharing & $\begin{array}{l}\text { Communication, ICT Literacy, Social \& Cross- } \\
\text { cultural skills }\end{array}$ \\
\hline Google Docs & Collaborative Productivity & $\begin{array}{l}\text { Collaboration, ICT Literacy, Flexibility \& } \\
\text { Adaptability, Productivity \& Accountability }\end{array}$ \\
\hline Podcasts & Post \& Comment & $\begin{array}{l}\text { Creativity \& Innovation, Critical Thinking \& } \\
\text { Problem Solving, Communication, Media } \\
\text { Literacy, ICT Literacy, Initiative \& Self-direction, } \\
\text { Leadership \& Responsibility }\end{array}$ \\
\hline $\begin{array}{l}\text { Video / Vcasts (e.g. } \\
\text { YouTube) }\end{array}$ & Post \& Comment & $\begin{array}{l}\text { Creativity \& Innovation, Communication, Media } \\
\text { Literacy, ICT Literacy }\end{array}$ \\
\hline 3D Worlds (e.g. Second Life) & Live Interactive & ICT Literacy, Communication \\
\hline Gaming, MMORPG's & Live Interactive & ICT Literacy, Collaboration \\
\hline Skype & Live Interactive & Critical Thinking \& Problem Solving, ICT Literacy \\
\hline Cellphone/Texting & Live Interactive & ICT Literacy, Communication \\
\hline Sploder & Game Creation & Creativity \& Innovation, ICT Literacy \\
\hline MindMeister & Organizers & Initiative \& Self direction, ICT Literacy \\
\hline Gradefix & Organizers & $\begin{array}{l}\text { Initiative \& Self direction, Leadership \& } \\
\text { Responsibility }\end{array}$ \\
\hline ¡Pod/iTunes & Knowledge Sharing & $\begin{array}{l}\text { Communication, ICT Literacy, Initiative \& Self } \\
\text { direction }\end{array}$ \\
\hline
\end{tabular}

Source: http://www.solutionwatch.com/512/back-to-school-with-the-class-of-web-20-part-1/ 
Implementing Web 2.0 technologies in the classroom 2.0 is in line with current 21 st century use of connectivism methods of instruction that serve to engage students, improve learning and provide development opportunities for teachers. "Emerging devices, tools, media, and virtual environments offer opportunities for creating new types of learning communities for students and teachers" where a learning community is one that fosters learning in collaborative ways [3]. This is important for the types of learning transformation that is beginning to emerge. Educators are looking at a more "participatory form of learning" where "the Internet is helping to drive [this] transformation" [11].

Web 2.0 enables all users to share creatively (pictures, YouTube videos, games), work collaboratively (blogs, wikis, mash-ups), and network globally (Facebook, Linked-in, Second Life $\left.^{\mathrm{TM}}\right)$. As others have suggested, Web 2.0 is a huge phenomenon that is very difficult to define succinctly [14]. Web 2.0 technologies have altered the learning environment through accessibility, consumerfriendliness, interactivity; networking capabilities, real-time learning opportunities, and collaboration that helps gather collective intelligence.

\section{21st Century Education}

21 st Century Educator" is probably the most popular buzzword in today's education. The term "21st century" has become an integral part of educational thinking and planning for the future. Educators and librarians are actively searching for ways to prepare students for the future, and the educational system has been evolving faster than ever before. We have gone from the machine age of the 19th century industrial revolution to the information age of the 21 st century. Education of the 20th century is therefore characterized by a "factory model" based upon the industrial age of the 19th century and the needs of employers.

The 21st centuryschools.com in a question and answer states as follows:

"So what is 21st century education? It is bold. It breaks the mold. It is flexible, creative, challenging, and complex. It addresses a rapidly changing world filled with fantastic new problems as well as exciting new possibilities"

The 21 st century education is a "global model" that meets the needs of a globalized, high-tech society. Learning in the 21 st century is researchbased, while 20th century learning is textbookdriven. The 20th century education is teachercentered with a fragmented curriculum that has students working in isolation and memorizing facts. Focus in learning in the 21 st century is about what students know, can do, and what the students are like long after details are forgotten. [www.capta.org/sections/...01/0921st_century\%20_e ducation.pdf].

[21] argue that education in the 21 st century requires a new way of teaching and learning with technology. The last century required schools to discipline students for work and life in a society that was the result of an industrial age, but the new century requires schools to prepare students for a society that needs different skills.

The skills, attitudes, values and competencies that will be needed have not always been addressed in traditional educational programmes. Student's resilience and ability to accept and adapt to change will determine success. Different approaches and methods of teaching are what many educationalists are calling for. [21]

\section{Characteristics of the 21st Century Teacher}

The 21st Century Learners are: collaborative, adaptive, information, media and technology savvy Communicators, immediate and instant and require instant gratification. They are creators and adaptors.

For now teachers are students-centric, holistic, they are teaching about how to learn as much as teaching about the subject area, but they must be $21 \mathrm{st}$ Century learners as well and even more than this.

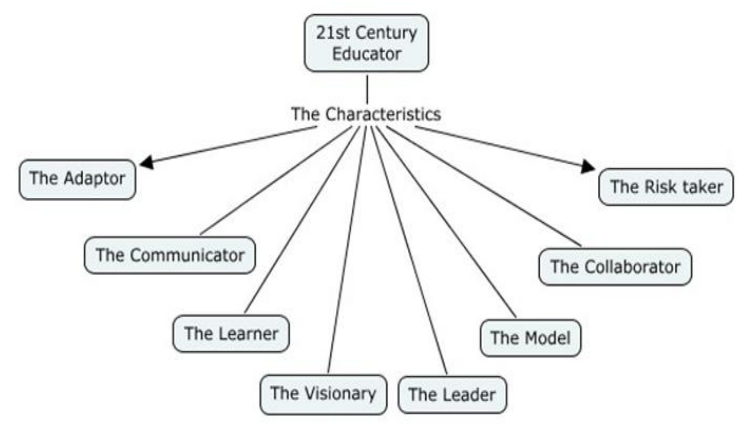

Figure 1. Source: 21st Century Teacher [edorigami.wikispaces.com/21st+Century+Teacher]

\section{Collaboration between Educators and Librarians}

According to [12] collaboration involves ongoing communication between educators and librarians about shared goals for student learning. Such ideal partnership is anchored on the premise that: each understands the other's role, views one another as partners and respects the expertise in the process of collaboration. They plan the goals together to achieve them, as well as share leadership, resources 
Table 2. The Strengths required by Educators and Librarians

\begin{tabular}{|l|l|}
\hline Librarians & Educators \\
\hline Skills for accessing new knowledge & Knowledge of the curricular content \\
\hline $\begin{array}{l}\text { An understanding of the inquiry process and } \\
\text { knowledge of the research process }\end{array}$ & Knowledge of the learning process \\
\hline Knowledge of print and electronic Resources & Knowledge of students \\
\hline $\begin{array}{l}\text { Knowledge of techniques for using technology to } \\
\text { enhance learning }\end{array}$ & Knowledge of teaching strategies \\
\hline $\begin{array}{l}\text { A repertoire of successful practices with a variety } \\
\text { of teachers, students, and technologies }\end{array}$ & $\begin{array}{l}\text { A repertoire of practices with a wide } \\
\text { variety of students }\end{array}$ \\
\hline
\end{tabular}

and responsibility in student learning. A successful collaborative practice requires both educators and librarians to know each other's strengths. Table 1 illustrates the various abilities in addition to the expertise required by educators as well as librarians for teaching.

These educators can also collaborate on teaching and assessment duties. Collaboration therefore brings educators and librarians together to assess the needs, while designing and implementing teaching and learning activities, as well as mapping the curriculum, and in the process, teach students to gain a heightened capacity of information literacy.

\section{The Role of Teachers, Librarians and Students in the 2.0 World}

The new teaching paradigm integrates discovery and experiential learning, while distancing itself from the traditional lecture-bound classroom [King 6, Friere3]. The teacher-centered instruction paradigm of the past 19th and 20th centuries is being replaced by a student-centred learning paradigm that is web-based and interactive. Under this new pedagogy there is an opportunity in considering the forces at play, to create new methods or models for how, when and where learning happens. These new models should reflect the learning context of our learners - their environments (physical and digital), their issues, their networks, their learning styles and the resources that will help them move from concept foundations, through concept exploration and on to concept application and feedback. Models such as this should show flexibility to allow for modalities of learning that include web and classroom-based experiences should incite learning in an engaging, meaningful and supported way.

Integrating technologies into teaching and learning is seen by many educators as affording opportunities to shift from teacher-centred to student-centred learning. Learning outcomes are the results that the educator expects the students/learners to attain. This has a direct connection to student/task outcomes as the educator will need to determine if the desired outcomes have been met. Teachers are therefore expected to create differentiated learning paths to accommodate the diverse needs of students within their classes and provide students with opportunities to take control of their learning activities As a result they face a significant challenge that lies in their ability to integrate Web 2.0 in their teaching practices, as Web 2.0 tools are not yet incorporated in classrooms, even in tertiary education.

The Librarian should become a facilitator; not telling students what is important for them to know, but creating an environment in which students can learn and have their ideas challenged. Librarians must ensure that our students have the skills necessary to successfully navigate the information environment of tomorrow and, for many, that will require a major shift in our approach to teaching. Students will need to develop the social and technical skills necessary to connect with information sources - both human and technological - in order to access new information. Students should be able to explore the answers to questions without feeling like there is only one right answer, since there is no one correct approach to research. Students should be given opportunities to work in groups to develop a collective understanding of information literacy and wrestle with specific information issues collaboratively. Students will also have to develop new literacies to be successful in the 2.0 Classroom and in the 2.0 world. As ideas about authority and knowledge have changed, so should notions about information literacy. There is need for collaboration between librarians and teachers. 


\section{Collaboration between Educators and Librarians}

According to [12] collaboration involves ongoing communication between educators and librarians about shared goals for student learning. Such ideal partnership is anchored on the premise that: each understands the other's role, views one another as partners and respects the expertise in the process of collaboration. They plan the goals together to achieve them, as well as share leadership, resources and responsibility in student learning. A successful collaborative practice requires both educators and librarians to know each other's strengths. Table 1 illustrates the various abilities in addition to the expertise required by educators as well as librarians for teaching.

These educators can also collaborate on teaching and assessment duties. Collaboration therefore brings educators and librarians together to assess the needs, while designing and implementing teaching and learning activities, as well as mapping the curriculum, and in the process, teach students to gain a heightened capacity of information literacy.

\section{The Role of Teachers, Librarians and Students in the 2.0 World}

Web 2.0 is still developing and will be subject to substantial changes as tools and applications evolve into web 3.0 and beyond. From a user, teacher or learner perspective, these potential applications blur and perhaps even erase the distinction between social 'web 2.0' and semantic 'web 3.0'. It seems likely that once appropriate tools and platforms are made widely available, elements and features of both genres will be integrated into new teaching and learning environments. The immersion of technology into a university's core pedagogy signifies not only striving for academic competitiveness, but also awareness that traditional 18th and 19th century bound face-to-face education is being transformed with or without our tacit consent and approval. Education is moving away from learning approaches founded on simple information sharing to one that relies on networking and other interactive technologies [19]. The new teaching paradigm integrates discovery and experiential learning, while distancing itself from the traditional lecture-bound classroom [10], [5]. The teacher-centered instruction paradigm of the past 19th and 20th centuries is being replaced by a student-centred learning paradigm that is web-based and interactive. Under this new pedagogy there is an opportunity in considering the forces at play, to create new methods or models for how, when and where learning happens. These new models should reflect the learning context of our learners - their environments (physical and digital), their issues, their networks, their learning styles and the resources that will help them move from concept foundations, through concept exploration and on to concept application and feedback. Models such as this should show flexibility to allow for modalities of learning that include web and classroom-based experiences should incite learning in an engaging, meaningful and supported way. One example of this is currently described as "blended programmes." Blended learning refers to an educational experience created cost-effectively using a mix of integrated distance learning technologies such as videoconferencing, e-learning, videos, and CDROM. It also includes the traditional face-to-face classroom activities, print resources, and a variety of instructional strategies such as action learning and participatory learning.

Integrating technologies into teaching and learning is seen by many educators as affording opportunities to shift from teacher-centred to student-centred learning. Learning outcomes are the results that the educator expects the students/learners to attain. This has a direct connection to student/task outcomes as the educator will need to determine if the desired outcomes have been met. Teachers are therefore expected to create differentiated learning paths to accommodate the diverse needs of students within their classes and provide students with opportunities to take control of their learning activities As a result they face a significant challenge that lies in their ability to integrate Web 2.0 in their teaching practices, as Web 2.0 tools are not yet incorporated in classrooms, even in tertiary education $[23,6]$.

The Librarian should become a facilitator; not telling students what is important for them to know, but creating an environment in which students can learn and have their ideas challenged. Librarians must ensure that our students have the skills necessary to successfully navigate the information environment of tomorrow and, for many, that will require a major shift in our approach to teaching. Students will need to develop the social and technical skills necessary to connect with information sources -both human and technological in order to access new information [21]. Students should be able to explore the answers to questions without feeling like there is only one right answer, since there is no one correct approach to research. Students should be given opportunities to work in groups to develop a collective understanding of information literacy and wrestle with specific information issues collaboratively. Students will also have to develop new literacies to be successful in the 2.0 Classroom and in the 2.0 world. As ideas about authority and knowledge have changed, so should notions about information literacy. There is need for collaboration between librarians and teachers. Collaboration involves ongoing communication 
between educators and librarians about shared goals for student learning. Such ideal partnership is anchored on the premise that: each understands the other's role, views one another as partners and respects the expertise in the process of collaboration.

\section{Conclusion and Recommendations}

Educators and librarians as [12] observe must work closely with students to design, implement, and revise their skills, to enable them to master the requisite information processing skills and understanding; to develop students as thoughtful and introspective learners; to enable students to acknowledge the value of independent and community-based learning; and, ultimately, to empower students with better self-sufficiency and social responsibility concerning the use of information.

Taking a cue from [17] e-Learning 2.0, Classroom 2.0 and Library 2.0 are up coming. So what do we do as Librarians 2.0 and Teacher 2.0? We need to:

- Try out the 2.0 applications.

- Learn to talk about the 2.0 capabilities, and not the weird names the products go by. Really we are talking about teaching and rendering service, publishing, editing, sharing, and collaborating just in new and better ways.

- Discuss with the other sections of the departments and library or other libraries to find out if they are deploying any new or upgraded software that you may be able to leverage.

- Appreciate and anticipate that these tools can and will change our culture of romance with technology and practice.

It is important for us to see that the most interesting thing is the idea that Web 2.0, Classroom 2.0, Library 2.0, Librarian 2.0 and Teacher 2.0 are all "a watershed" for our profession. The 2.0 phenomenon will make us see and experience a cultural change in the knowledge industry.

Learning-centered strategies and approaches place increased emphasis on innovative learning pedagogies and in increased student-faculty interactions. The learning-centered roles of the librarians, faculty and students; shift faculty and indeed librarians from being the knowledge keeper, to being knowledge facilitators, and their students from being passive learners to active learners. Teachers must engage in the proactive use of Web 2.0 technologies. Nevertheless, it must be recognized that technology is not of itself the sole driver of pedagogical change. Technological resources provide opportunities for a range of interactions, communicative exchanges, and sharing, but it is not possible to base an entire sequence of learning episodes solely on tools. The 21 st century will require knowledge generation, not just information delivery, and schools will need to create a "culture of inquiry". Schools 2.0 and Classroom 2.0 will go from 'buildings' to 'nerve centers', with walls that are porous and transparent, connecting teachers, students and the community to the wealth of knowledge that exists in the world."

The curriculum is not textbook-driven or fragmented, but is thematic, project-based and integrated. Teacher 2.0- primary role will change from dispenser of information to orchestrator of learning and helping students turn information into knowledge, and knowledge into wisdom.

Learner 2.0 - must be seen in a new context:

- By maintaining student's interest and preparing them for life in the real world.

- By imbibing curiosity and spirit of inquiry, this is fundamental to lifelong learning.

- Flexibility in how we teach them through blended learning

- Exciting learners to become more resourceful to enable them continue to learn outside the formal school day.

The digital age is here and the success of technology infusion in education is anchored over 'teacher-training.' It is therefore imperative that educators must embrace the 21 st century learning paradigm shift to ensure that students are adequately prepared for the global workforce. Many of the technologies available for use are user-friendly. With the thought of bringing the 'world' into the classroom 2.0 to provide real world experiences, educators should continue to adopt technology. However, the availability of state-of-the-art resources, effective and continuous training and teachers' willingness to adopt new technologies are primary requirements of Teacher 2.0 to enhance Pedagogy 2.0 in Classroom 2.0 using Web 2.0. For Librarian 2.0 he is a facilitator who creates Library 2.0 for Learners 2.0 to acquire knowledge in the World of Learning 2.0.

\section{References}

[1] Anderson, P., What is Web 2.0? Ideas, technologies and implications for education.

Technical report, JISC, http://www.jisc.ac.uk/ media/documents/techwatch/tsw0701b.pdf 2007

[2] Dede, C., (2008). "Distributed Learning Communities." Harvard Graduate School of Education. www.gse.harvard.edu/ dedech/ 505/Distributed-Learning_Communities.pdf >.

[3] Farkas, M. G. Participatory technologies, pedagogy 2.0 and information literacy Library Faculty Publications and Presentations. Paper 
73.Retrieved from http:// dxscholar.library.pdx. edu / ulib fac /73, 2008.

[4] Farkas, M. G., (2012). Participatory technologies, pedagogy 2.0 and information literacy Library Faculty Publications and Presentations. Paper 73 http://pdxscholar.library.pdx.edu/ulib_fac/73

[5] Freire, P., (2007). Pedagogy of the oppressed. New York: Continuum.

[6] Garcia, P., \& Qin, J., (2007). Identifying the generation gap in higher education: where do the differences really lie? Innovate: Journal of Online Education, 3(4). http://www.editlib.org/p/104229

[7] Habib, M.Conceptual model for academic library 2.0. Michael Habib's weblog on library and Information science. Accessed June 10,2006, from http://mchabib.blogspot.com/2006/06/conceptualmodel-for-academic-library.html, 2006

[8] Holmberg, K., (2009). What is Library 2.0?: Journal of Documentation: Vol 65, No 4 - Emerald, www.emeraldinsight.com/doi/pdf/10.1108/00220410 910970294

[9] Hutagalung, N.Classroom 2.0, an upgrade to teaching and earner; teachertechblog.com/ category/Community, 2007.

[10] King, B. J. "Web 2.0 and education: literature review of tools and technologies to enhance education." http://www.scribd.com/doc/9010043/ Web-20-Tools-for-Higher-Education-LiteratureReview-by-Brian-J-King.2011

[11] LaMonica, M., (2008). "Futurist: To fix education, think Web 2.0 - CNET News." Technology News - CNET News. Retrieved from <http://news.cnet.com/2100-1032_3-6140175.html? part=rss\&tag=2547-1023_3-0-5\&subj=news $>$.

[12] Lai, J. and Wei, D., (2013). Collaboration between teachers and librarians for information literacy curriculum: a case study of a Hong Kong secondary school Journal of Studies in Education 3(3), http://dx.doi.org/10.5296/jse.v3i3.3859

[13]Maness J.M,Library 2.0 Theory: Web 2.0 and Its Implications for Libraries. Webology vol.3 no 2, 2000.

[14] Mareguesan, S., (2007) "Understanding Web 2.0." IT Professional Magazine 9 (4): 34-41. ABI/INFORM Global. (Document ID: 1326203811).

[15] McCarthy, J., (2010). Blended learning environments: using social networking sites to
Enhance the first year experience. Australasian Journal of Educational Technology, 26(6), 729-740. http://www.ascilite.org.au/ajet/ajet26/mccarthy.html

[16] McLoughlin, C. \& Lee, M. J. W., (2008) The three P's of pedagogy for the networked society: Personalization, participation, and productivity. International Journal of Teaching and Learning in Higher Education 20 (1). 10-27. Retrieved from http://www.isetl.org/ijtlhe/pdf/IJTLHE395.pdf

[17] Mc. Loughlin, C. \& Lee, M. J. W. (2008) The three P's of pedagogy for the networked society: Personalization, participation, and productivity. International Journal of Teaching and Learning in Higher Education 20 (1). 10-27. Retrieved fromhttp://www.isetl.org /ijtlhe/pdf/IJTLHE395.pdf, 2008

[18] Oehlert, M., 2008 Change 2.0: How Does ELearning 2.0 Affect Organizational Culture?, www.learningsolutionsmag.com/authors/86/

[19] O'Reilly, T., (2005). Web 2.0: Compact definition? Blog entry at O'Reilly Radar. URL:http://radar.oreilly.com/archives/2005/10/Web_ 20_compact_definition.html

[20] Schaller, D. R., and Allison-Bunnell, S. (2003). Practicing what we teach: how learning theory can guide development of Online educational activities." Paper presented at Museums and the Web 2003, Charlotte, NC. http://www.archimuse.com/ msw2003papers/schaller/schaller.html.

[21] Siemens, G., (2005b): Connectivism: Learning as Network-Crreation, www.learningcircuits.org/ 2005/nov2005/seimens.htm, accessed 7 April 2007)

[22] Snape, P. \& Fox-Turnbull, W., (2011). Twentyfirst century learning and technology education nexus. Problems of Education in the 21st Century, 34: $149-161$.

[23] Tammets, K. Tammets, P. and Laanpere, M. (n.d.).Introducing Open Classroom 2.0 to Teachers through Immersive Learning. Retrieved from.ttps://www.etis.ee/portaal/isikuCV.aspx? PersonVID=57571.

[24] Tomlinson, C. A., (1999). The differentiated classroom: responding to the needs of all learners. Alexandria, VA: Association for Supervision and Curriculum Development.

[25] Wenglinsky, H., (2005). Using technology wisely: the keys to success in schools (Technology, Education-Connection). New York: Teachers College Press. 